\title{
"Las ciencias sociales tienen una deuda ominosa con la humanidad..."
}

\author{
José Sánchez Jiménez
}

Jesús Ruvalcaba Mercado, 2008

Ética, compromiso y metodología: el fundamento de las ciencias sociales

Centro de Investigaciones y Estudios Superiores en

Antropología Social, México, 194 pp.

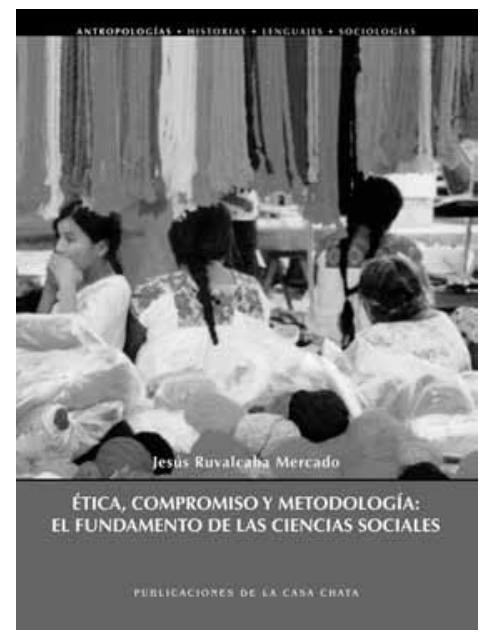

ominosa con la humanidad que ni con mucho lograrán saldar" ( $\mathrm{p}$. 46). La deuda con la humanidad es una resonancia del eco marxista sobre la emancipación como proyecto libertario.

Mientras que las ciencias sociales, en particular la antropología, analicen su objeto de estudio sin considerar la historicidad y su singularidad, las conclusiones a las que se arriben serán siempre deudoras, no es suficiente con una ciencia descriptiva, más bien será necesario incorporar las dimensiones del compromiso social con los pares y el contexto de estudio, así como establecer caminos de veracidad y objetividad en la producción del dato. Lo que nos propone el texto es tomar el objeto de estudio sin 
renunciar a los ideales de objetividad, la veracidad y la falsabilidad de los datos, pero incorporando la reflexión sobre el uso y función de los discursos sociales que habilitan tanto el compromiso social como la responsabilidad social.

Definir los conceptos es algo necesario. Y debido a la múltiple procedencia de los conceptos propuestos el texto parece romper su idealidad. El dictum de que las ciencias sociales no podrán saldar su deuda con la humanidad no es precedido de ningún condicional, de manera que el pesimismo del autor se trueca en la esperanza de que habrá que comenzar por algún lugar. Para que su propuesta tenga lugar ha debido aludir justamente a un principio de diferenciación y comparación, práctica común $y$ arraigada entre los etnógrafos. Asume que al contrastar diversas definiciones de ética tomadas de diccionarios, así como las configuraciones profesionales de cientistas sociales franceses o norteamericanos, el de

Latinoamérica encontrará que su oficio está sujeto a contextos históricos de desigualdad social. En cualquiera de sus vertientes, esta asimetría pesa y preocupa a Ruvalcaba, por lo que todo su esfuerzo se dirige a crear condiciones para romper las asimetrías de la desigualdad: pobreza, poderes estatales, caciquiles, violencia de género y racismo, entre otros. Justo desde aquí, lo que el autor entiende por ética, más allá de haber citado definiciones de diccionario y de distinguir entre ética como estudio o indagación del bien, de la moral como el ejercicio personal de principios y valores seguidos de la reflexión o del obrar, consiste en hacer justicia a la formación profesional inculcada por Ángel Palerm: lo que se estudia son las interrelaciones mutuas del hombre, la sociedad y la cultura consideradas evolutivamente. Todo ello con el fin de que el conocimiento generado por el antropólogo sirva para resolver los problemas acuciosos de la humanidad, es decir, la desigualdad en cualquiera de sus manifestaciones.

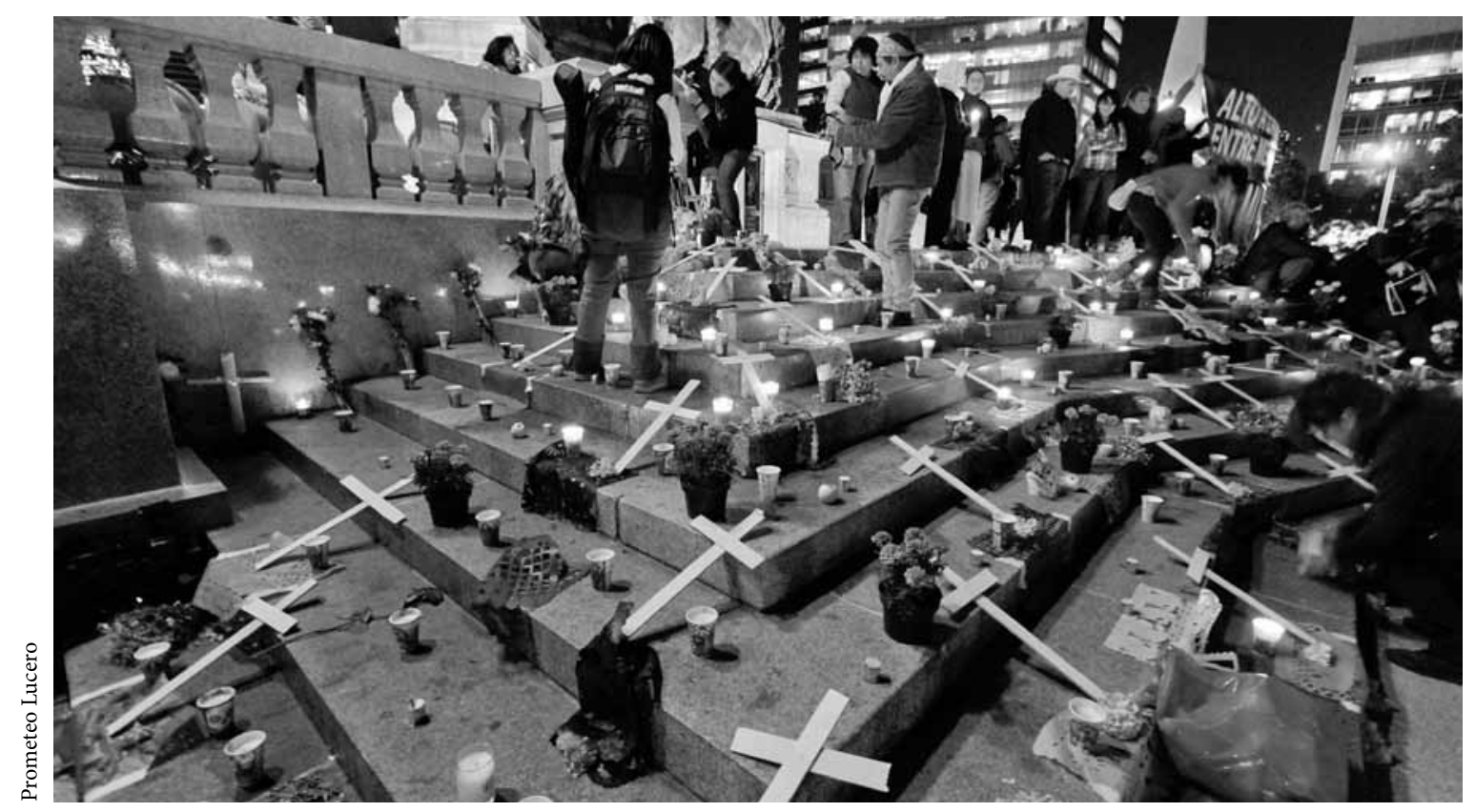

Acto del Movimiento por la Paz con Justicia y Dignidad en el Ángel de la Independencia durante el Día de Muertos, 31 de octubre de 2011. 
Sin embargo, hay algunas inconsistencias que es necesario señalar para abrir nuevas conexiones en la discusión que ha emprendido Jesús Ruvalcaba. A ellas me habré de referir brevemente y concluiremos sobre lo que hace posible las interconexiones entre "ética, compromiso y metodología como fundamento de las ciencias sociales". Primero, pensar que una constitución política es un código de ética que puede normar las relaciones profesionales es algo que debe discutirse con amplitud y a la luz de lo que se considera justo. Se apela a la idealidad del Estado de derecho a partir de preceptos como el de no violentar el

derecho de terceros, para afirmar más tarde que la singularidad de contextos y personajes que actúan como fuerzas vectoras de lo social influyen en las ciencias sociales al confrontar al investigador con discursos e instituciones que contravienen ellas mismas, no menos que algunos oficiantes de antropología, el derecho de terceros. En consecuencia, el debate debiera mostrar la confrontación entre una concepción ética heterónoma versus una autónoma.

Más tarde se analizan las distinciones conceptuales. Ética aparece como código normativo, como reflexión sobre principios éticos, e incluso como la concepción del bien común y sus límites. Moral es una práctica: alguien se conduce de manera moral o inmoral, sea que sus actos hayan estado acompañados o no de una reflexión o con apego a principios. Es aquí donde Ruvalcaba ubica la intención práctica del texto: una guía metodológica sobre cómo conducirse en terreno con apego a objetividad y destacando el compromiso social del investigador con el contexto. Por último, el compromiso y la responsabilidad. Estos aspectos son introducidos desde la perspectiva supuestamente metodológica y desde la progresión "sociológica" que nos lleva, curiosamente, desde Hume hasta Durkheim y Weber y sobre todo hacia Marx. El mayor peligro, según Jesús Ruvalcaba, consiste en que el investigador sucumba al canto de las sirenas en sus variantes estatales, económicas y de poder. Su compromiso debe ser social. Su conciencia "ética", si es que traducimos bien la intención de autor, debe orientar y guiar el proceso de investigación, dado que la relación entre sujeto y objeto, por la vía del contexto en que se inserta su práctica profesional, conforma una "unidad conceptual". Su solución supone la idealidad del científico como sujeto apegado a la ética. No considera, siendo consistente con la visión evolutiva que propone, que las formas de conciencia moral muestren una relación de simetría entre cultura y sociedad. En este sentido, el etnógrafo no posee ventaja sobre sus pares y ellos tampoco serán víctimas. Una posible alternativa para el debate podría ser: ¿cómo hacer de las ciencias sociales un oficio público, sujeto a revisión y crítica? Y cuando propongo "público" me refiero justamente a lo que Ruvalcaba detesta de la formación antropológica: que no sea un oficio hermético y dogmático, sino reflexivo y autocrítico.

Al final nos quedamos con una duda: la relación entre ética, compromiso y metodología ¿es de orden conceptual, filosófica o práctica? La respuesta del autor se orienta a proponer una guía práctica para estudiantes donde se destacan diversos problemas de relaciones sociales, desde los que se califica una forma de hacer antropología y se descalifica otra, una forma de otorgar relevancia social a los objetos de estudio y otra para restarla. Entre estas oposiciones se entiende que la antropología, y quizá las ciencias sociales en su conjunto, ya no el autor, deben considerar - compromiso ético- el contexto desde donde se escribe para superar el plano descriptivo y resarcir el compromiso de las ciencias sociales con la humanidad: "una deuda ominosa que no podrán saldar". 